\title{
Technological aspects of the synthesis of 2,4-dichlorophenol
}

\author{
Arkadiusz Białek, Wiesław Moszczyński \\ Institute of Industrial Organic Chemistry, (IPO), ul. Annopol 6, 02-236 Warszawa, Poland, e-mail: BS7@ipo.waw.pl
}

\begin{abstract}
The main factors influencing the selectivity of chlorophenols synthesis were described. The loss of raw materials and the composition of wastes obtained in a conventional technology of 2,4-D production based on 2,4-dichlorophenol (2,4-DCP) of the $89 \%$ purity were presented. The influence of some homogenous catalysts on the selectivity of 2,4-dichlorophenol obtained in phenol and chlorine reaction was examined. Using the combined catalyst enables to chlorinate selectively the monochlorophenols to 2,4-DCP without an undesirable increasing of the 2,6-dichlorophenol and 2,4,6-trichlorophenol contents. The catalyst transformations during the reaction of phenol chlorination were investigated and the method of its elimination after the reaction was elaborated.
\end{abstract}

Keywords: 2,4-dichlorophenol, chlorination, catalyst, dioxine, 2,4-dichlorophenoxyacetic acid.

\section{INTRODUCTION}

2,4-Dichlorophenol (2,4-DCP), with $p$ - and $o$ monochlorophenols, 2,6-dichlorophenol (2,6-DCP) and 2,4,6-trichlorophenol (2,4,6-TCP), belongs to the group of ,light chlorophenols”. They are widely used in organic synthesis in the production of pharmaceuticals, disinfectants, preservatives, insecticides, fungicides, herbicides and other active substances. The most important in this group is 2,4-DCP, an intermediate product in the synthesis of 2,4-dichlorophenoxyacetic acid (2,4-D), the selective herbicide that is of great importance in crops, rice, sugar cane and other massive cultivations.

The worldwide 2,4-dichlorophenol ${ }^{1,2}$ production figures for 1989, excluding Russia, Eastern Europe, China and India are:

$\begin{array}{ll}\text { Western Europe } & 14000 \mathrm{Mg} / \mathrm{yr} \\ \text { USA } & 19000 \mathrm{Mg} / \mathrm{yr} \\ \text { Asia } & 11000 \mathrm{Mg} / \mathrm{yr} \\ \text { Total } & 44000 \mathrm{Mg} / \mathrm{yr}\end{array}$

At the present moment $6000-8000 \mathrm{Mg} / \mathrm{yr}$ of 2,4dichlorophenol is produced in Poland, which gives us a high place in the world ${ }^{3}$. Rhone-Poulenc, with the capacity of around $20000 \mathrm{Mg} / \mathrm{yr}$, is the world's leading producer of light chlorophenols.

Industrial manufacturing of $2,4-\mathrm{DCP}$ in the world is based on the chlorination of melted phenol with gaseous chlorine. By using $2 \mathrm{M}$ of chlorine for $1 \mathrm{M}$ of phenol at the temperature of $50-60^{\circ} \mathrm{C}$ it is possible to obtain 2,4DCP demonstrating the maximal purity of $88-89 \%$ and the composition that has been presented in Table 1 .

The method of the 2,4-DCP synthesis mentioned above, having been used since the forties, is cheap, easy to realize industrially and can be described as a ,conventional technology". The shortcoming of this technology is the poor quality of the product, which contains undesirable chlorophenols, the quantity of which amounts to 11 $12 \%$. Isolation of 2,4-DCP from the other chlorophenols is difficult because of similar physical and chemical properties of chlorophenols. Three components: 2,4-DCP, $p$ chlorophenol and 2,6-DCP have similar boiling points at the temperature of $210-220^{\circ} \mathrm{C}$. Rectification of $89 \% 2,4-$ dichlorophenol on the vacuum column of 25 theoretical plates to the product with the purity of $96 \%$ results in losses of chlorophenols in the quantity of $1 \%$ in the forerun and $14 \%$ as the after-run (distillation pot) ${ }^{4}$.

In the synthesis of 2,4-D, all chlorophenols that are contained in the technical 2,4-DCP, undergo reaction with monochloroacetic acid giving as a result a mixture of chlorophenoxyacetic acids containing about $88 \%$ of 2,4$\mathrm{D}$ acid. Purification of 2,4-D usually applied in industry is based on the crystallization of sodium salt, which enables to obtain its maximal purity of $96 \%$. The synthesis and purification of 1 ton of 2,4-D give about 10 tones of wastes containing unreacted chlorophenols, chlorophenoxyacetic acids, glycolic acid and sodium chloride. Many thousand tones of 2,4-D a year are produced worldwide so it becomes a serious ecological problem.

The selectivity of phenol chlorination to 2,4dichlorophenol influences the whole technology of the process, the quality of 2,4-D and the costs of the production.

It is obvious here how true the statement given by $\mathrm{W}$. Bartmann and B.M. Trost, „Selectivity is a major goal in modern synthetic chemistry" is.

Over the last three decades great interest in the improvement of phenol chlorination selectivity has been observed, which is related to 2,4-D manufacturing. It can be easily seen in an increasing number of scientific publications and patents. Three facts responsible for this situation are as follows:

Table 1. The composition of technical 2,4-dichlorophenol and the characteristics of its components

\begin{tabular}{|l|c|c|c|c|}
\hline Component & $\begin{array}{c}\text { Content } \\
{[\%]}\end{array}$ & $\begin{array}{c}\text { Melting point } \\
{\left[{ }^{\circ} \mathrm{C}\right]}\end{array}$ & $\begin{array}{c}\text { Boiling point } \\
{\left[{ }^{\circ} \mathrm{C}\right]}\end{array}$ & $\begin{array}{c}\text { Solubility in } \mathrm{H}_{2} \mathrm{O} \text { in } 20^{\circ} \mathrm{C} \\
{[\mathrm{g} / \mathrm{l}]}\end{array}$ \\
\hline o-chlorophenol & 2.0 & 8.7 & $175-176$ & 28.5 \\
\hline 2,4-dichlorophenol & 88.5 & 42.8 & 210 & 4.5 \\
\hline$p$-chlorophenol & - & $40-41$ & 219 & 27.1 \\
\hline 2,6-dichlorophenol & 8.0 & 67 & $219-220$ & no data \\
\hline 2,4,6-trichlorophenol & 1.5 & 68 & 244.5 & 0.8 \\
\hline
\end{tabular}


- Finding dioxins in 2,4,5-trichlorophenol after the accident in Seveso in 1976.

- European Community Directive No. 91/414/EEC about the reassessment and registration of all pesticides.

- New law regulations concerning environment protection (REACH).

On 10 July 1976 in ICMESA factories in Seveso near Milan, an explosion and dissipation of wastes from the production of 2,4,5-trichlorophenol took place. The environment was contaminated with kilograms of 2,3,7,8tetrachlorodibenzo- $p$-dioxine (TCDD), which is considered to be a highly cancerigenous compound. Octachlorodibenzo- $p$-dioxins, having been known earlier, which are formed in big amounts during the production of pentachlorophenol and numerous cases of intoxication and chloracne that were found in different countries, have never been linked to dioxins ${ }^{5}$. The discovery of this connection after the accident in Seveso caused an avalanche of research concerning the synthesis of chlorophenols and attendant dioxins.

In 1991 the 91/414/EEC directive and some executive directives treating the registration and admission onto the market of all pesticides were published ${ }^{\mathbf{6}}$. The main condition was to do a new physical and chemical research and toxicological and ecotoxicological assessment of active substances and contaminants present in pesticides in the amount higher than $0,1 \%$.

The directive in which health and environment protection were of greatest importance, was also the reason for market blockage against cheaper pesticides of lower quality from Eastern Europe and Asia.

New, more stringent regulations in environment protection concerned toxic and dangerous substances trade, dangerous wastes and chemical by-products produced during the industrial production. It is necessary to mention that some of pesticide producers had been gathering by-products on waste-heaps for years and they had been disposing of wastes directly into the sea without sufficient refining. Inactive isomers of $\mathrm{HCH}$ obtained in lindane production and chloroorganic by-products from 2,4-D manufacturing are one of such examples.

\section{LITERATURE}

Phenol is a substrate that easily undergoes electrophylic substitution in the aromatic ring. Additional pair of electrons from hydroxyl group after delocalization and because of messomerism shifts to moves in aromatic ring, which results in a higher density of electrons in ortho- and para- positions.

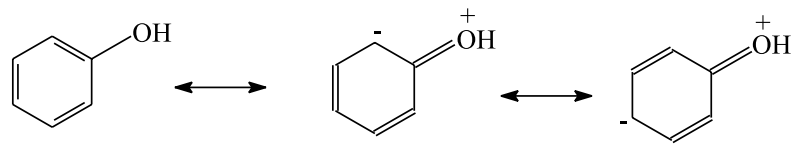

Substitution in the ring with an electrophilic agent is fast but not regio- and chemoselective. Just after using 1 $\mathrm{M}$ of chlorine for $1 \mathrm{M}$ of phenol a mixture of six products is formed ${ }^{7}$.

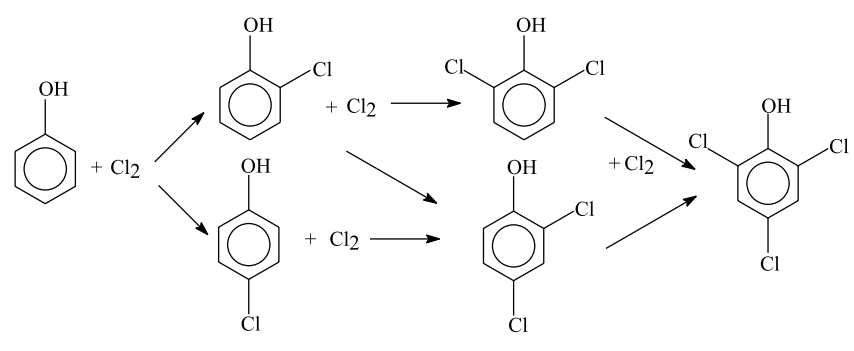

The following conclusion can be drawn from the scheme above: obtaining $p$-chlorophenol as an intermediate product in the synthesis of 2,4-dichlorophenol is much more advantageous than obtaining $o$-chlorophenol which is followed by forming 2,4-dichlorophenol and 2,4,6trichlorophenol or even 2,6- dichlorophenol. Further analysis of each chlorophenol production scale provides answers to the question why most publications are so interested in the $p$-chlorophenol synthesis.

The selectivity of reaction is dependent on many factors; one of them is the density of the electrons in the molecule of the substrate. The active centers in the phenol are situated in ortho- and para-positions; the para-position is preferential. The dissociation of hydroxyl group under various $\mathrm{pH}$ conditions influences the direction of electrophyllic substitution. The activity of the electrofillic agent is a factor of major importance. The chlorine molecules work as a strong electrophylic agent, rapidly reacting with active aromatic substrates. The steric effect and the influence of the catalysts should also be taken into consideration. In the melted phenol intermolecular hydrogen bonds with the hydroxyl group are formed. Association of molecules makes the substitution in the orthoposition difficult. A similar effect can be found during the chlorination of phenol in strong acids and polar protonated solvents. The presence of a hydrogen bond was proved with the aid of IR methods and proton $\mathrm{NMR}^{\mathbf{8}, 9,10}$.

Wastson carried out the chlorination of phenol in $\mathrm{CCl}_{4}$ with gaseous chlorine and $t-\mathrm{BuOCl}$, and the influence of hydrogen bonds on the ortho-/para-chlorination ratio was revealed $^{\mathbf{1 1}}$. It was proved that the yield of $o$-chlorophenol forming in phenol chlorination with chlorine depends proportionally on phenol concentration in the solvent taken into the reaction $\left(\mathrm{CCl}_{4}\right)$. The least yield of $o$-chlorophenol isomer is obtained when the reaction is carried out in melted phenol. The ratio of $o$-chlorophenol to $p$-chlorophenol in the post-reaction mixture is 0,65 when the reaction is carried out in melted phenol and it increases up to 2,5 when the reaction is carried out in the $5 \%$ solution of phenol in $\mathrm{CCl}_{4}$. Comparable results were obtained by Ogata and co-workers who proved a strong dependence of chlorination selectivity on the sort of the solvent used ${ }^{\mathbf{1 2}}$.

It is not necessary to use a catalyst during the synthesis of 2,4-dichlorophenol from melted phenol and gaseous chlorine. The process of chlorination stops at 2,4,6trichlorophenol. Substitution of the next chlorine atoms is only possible when Friedel-Crafts catalysts are used.

Industrially three groups of regioselective catalysts of electrophyllic substitution of phenolic compounds are known: amines, the derivatives of bivalent sulfur and combined, which are derivatives of bivalent sulfur and 
Lewis acids - they are used with various chlorination agents such as gaseous chlorine, sulfuryl chloride, hypochlorites.

Primary, secondary and tertiary amines when taken in trace amount with phenol solutions in organic solvents direct atoms of chlorine into ortho- position ${ }^{13}, 14$.

High para- selectivity (98\%) in the synthesis of 4-chloro2-methylphenoxyacetic acid (MCPA) by the chlorination of 2-methylphenoxyacetic acid in water with hypochlorites in the presence of tertiary amines and dimethylaminacetic acid dimethylamide has been obtained ${ }^{15}$. The catalytic influence of diphenyl sulfide (DPS) and other derivatives of bivalent sulfur has been described ${ }^{\mathbf{1 6}}$. The activity of those catalysts is comparable to $\mathrm{AlCl}_{3}$, while by using sulfur and $\mathrm{AlCl}_{3}$ combined, the ratio $p$ - $/ o$ - is doubled from 1,6 to 3,2 and it also the time of reaction of phenol with chlorine is made shorter ${ }^{7}$. The following mechanism has been proposed for the catalytic activity of sulfide:

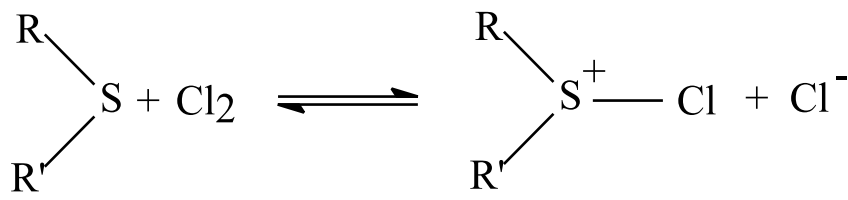

According to Rhone-Poulenc patent description ${ }^{18}$ the selectivity of phenol monochlorination with chlorine, which is expressed by the ratio of $p$ - $/ o$ - isomers, increases up to 3,06 when the catalysts of $R_{1}-S-R_{2}$ formula or metaloorganic derivatives of ditiophosforic acid are used. Using only Lewis acids such as $\mathrm{AlCl}_{3}$ does not change the selectivity of monochlorination. In the mentioned publications no improvement of dichlorination selectivity was reached, unsatisfactory amounts of 2,4,6-trichlorophenol were formed in spite of making the process slower and diluting chlorine with neutral gas. Research into the phenol reaction $(47 \mathrm{~g})$ with molar amounts of chlorine in the presence of diphenyl sulfide $(0,5 \mathrm{~g})$ was carried out by Serg Ratton, resulting in obtaining the composition of the postchlorination mixture as follows:

$o$-chlorophenol

p-chlorophenol

$21,7 \%$

2,4-dichlorophenol

(4) $66,5 \%$

$11,3 \%$

$0,55 \%$

$2,6-$ dichlorophe
$p-/ o-=3,06$

The time of the chlorination was 2 hours and $15 \mathrm{~min}$ utes. The author shows that an increase of the temperature up to 80 and $100{ }^{\circ} \mathrm{C}$ results in making the ratio $p$-/ $o$ - lower to 2,32 and 1,9, respectively.

Shelton and co-authors ${ }^{19}$ patented phenol chlorination by means of chlorine in the presence of 0,005 to about $0,016 \mathrm{M}$ of acid catalyst belonging to Lewis acids group for $1 \mathrm{M}$ of phenol and sulfur co-catalyst belonging to group comprising sulfur, thiophenol, $p$-chlorothiophenol, $p, p^{\prime}$-dichlorophenyl sulfide, benzyl disulfide, diphenyl sulfide or other substances that can form an active com- plex. The authors illustrate the complex formation presenting the following example:

Watson claims that by using GLC it was determined that diphenyl sulfide (DPS) does not provide reaction of the chlorination and it can be regenerated in the same form ${ }^{17}$.

Tzimas and co-authors describe in patents that the catalytic compositions of DPS with metal halogens are not always suitable for industrial scale. It is difficult to extract them after reaction, many sulfur compounds have arduous properties like smell, metal halogens hydrolyze with water affording hydrogen chloride which is responsible for corrosion, it is impossible to reuse them, which makes the costs of the production increase ${ }^{20,21}$. Moszczyński, Białek and others patented the synthesis of 2,4-DCP of high purity $95 \%$ with the use of a catalytic complex, which contains Lewis acid and bivalent sulfur compounds ${ }^{22}$.

Another problem appearing in the production of 2,4dichlorophenol are trace contaminants of high toxicity. The LD in rates for all the light chlorophenols is between 130 and $4000 \mathrm{mg} / \mathrm{kg}$ body weight. The toxicity of these compounds in the order of their decreasing strength is: monochlorophenols $>$ dichlorophenols $>$ trichlorophenols. Chlorophenols, in lethal doses affect the central nervous system. Chlorophenols induce free radicals, responsible for erythrocyte damage ${ }^{23}$.

Chlorophenols are not carcinogens. The toxicology of chlorophenols is made more complicated by the presence of microcontaminants, such as polychlorophenoxyphenols and polychlorodibenzofurans in technical products. For the purpose of analyzing the purity of technical chlorophenols gas chromatography is recommended ${ }^{24}$. However, this method is not sensitive enough because of gem-dichlorohexadienones present at different steps of the production, which are decomposed to lighter chlorophenols. The HPLC method seems to be more accurate $^{25}$.<smiles>O=C1C(Cl)=CC(Cl)(Cl)CC1Cl</smiles><smiles>Oc1c(Cl)cc(Cl)cc1Cl</smiles>

In the synthesis of 2,4-DCP, isomeric 2,6-DCP (about $8 \%$ ), o-chlorophenol (about 2\%) and 2,4,6-trichlorophenol (about $1,5 \%$ ) are the main contaminants, with $o$-chlorophenol being the least desirable. Contrary to 2,6-DCP it is difficult to isolate and it determines the quality standard of 2,4-D. 2,6-DCP is the main source of 2,4,6trichlorophenol and trace contaminants - unsaturated gemdichlorocyclohexenones.<smiles>CCC(C)C(CC)C(CC)c1ccc([SH]([Al])(Cl)(c2ccc(Cl)cc2Cl)c2ccc(Cl)cc2Cl)c(Cl)c1</smiles> 
<smiles>O=C1C(Cl)=CC=CC1(Cl)Cl</smiles>

2,4,5,6,6-pentachloro-2-cyclohexen-1-one
During the chlorination of 2,6-dichlorophenol with chlorine to $\mathrm{PCP}$ at $70^{\circ} \mathrm{C}$, pentachlorocyclohexenone reaching the amount of $15 \%$ is obtained. Such compounds are not obtained during the high selectivity para-chlorination in the presence of catalysts based on strong acids ${ }^{26}$, sulfur ${ }^{27}$, amines $^{28}$. When the chlorination of 2,4-DCP and 2,6-DCP to 2,4,6-trichlorophenol is carried out it is possible to obtain isomer 2,4,5-TCP related to 2,4,6-TCP from 0,003 to $0,010 \%$. During the chlorination of $2,6-\mathrm{DCP}$ large amount of 2,4,5,6,6-pentachloro-2-cyclohexanone is formed $^{29}$. The mixture of chlorophenols is unstable. In the synthesis of tri-, tetra-, pentachlorophenols the colour change of chlorophenols is noticed during the chlorination, stops, transport, storage and distillation, which is caused by the formation of chlorophenoxyphenols.

According to Desmurs and Ratton's patent ${ }^{29}$, the source of these contaminants is an increase of phenoxyphenols percentage in the chlorophenols mixture. The product of distillation is also unstable. The presence of unsaturated cyclic ketones with the gem-dichloro group is responsible for this instability. A lot of reducing agents, which are acceptors of chlorine, are mentioned in the patent, for example organic phosphorites, organic sulfides, metal hydrides, metals, phenols, chlorophenols, alkylphenols and dihydroxynaphtalenes. Such reductants stabilize the mixture obtained during phenols and chlorophenols chlorination in such a way that gem-dichloro unsaturated cyclic ketones are converted into chlorophenols or they react with cyclic ketones, giving heavy compounds such as biphenyls and phenoxyphenols as products.

According to some publications, during the chemical or thermal decomposition of chlorophenols polychlorodibenzodioxins (PCDD) and polychlorobenzofurans (PCDF) are formed.

In light chlorophenols trace amounts of PCDD and PCDF can appear when monitoring of the phenol chlorination process is not sufficient, but the most toxic $2,3,7,8$ tetrachloroparadioxin has never been found ${ }^{\mathbf{1}, 2}$. Russian publications $^{\mathbf{3 0}}$ indicate that the content of 2,3,7,8-TCDD in their home production reaches $0,29 \mu \mathrm{gTEQ} / \mathrm{kg}$ and $0,5 \mu \mathrm{gTEQ} / \mathrm{kg}$ in amine salts of 2,4-D which are produced in Bashkiria. Trace amounts of dioxins can be found in herbicides 2,4-D and 2,4-DP (2,4dichlorophenoxypropionic acid $)^{\mathbf{3 1}}$. According to the United Nations Organization report, the ratio of PCDD/F emis- sion for 2,4-D acid reaches $700 \mu \mathrm{g}$ TEQ / tone, the real content is various and can range from $3 \mu \mathrm{g}$ TEQ/tone to $200 \mu \mathrm{g}$ TEQ/tone. The ratio for dichloroprop (2,4-DP) obtained from 2,4-dichlorophenol reaches about 1000 $\mu \mathrm{gTEQ} /$ tone. $2,4-\mathrm{D}$ is belived to be the source of dioxins, but it contains only congeners, which are not substituted in 2,3,7,8- positions, so they are not considered to be toxicologically dangerous ${ }^{32}$.

According to the USA patent, adding at least $0,5 \%$ by weight of glycolic ether to chlorophenol just after the end of chlorination inhibits dioxins formation, chlorophenol decomposition and it results in chlorophenol which remains melted. It prevents the steel containers and steel containers lined with plastics from corrosion ${ }^{\mathbf{3 3}}$.

\section{EXPERIMENTAL}

Melted phenol chlorination to 2,4-dichlorophenol using chlorine with the aid of conventional method without catalysts

Phenol was melted and in the amount of $25 \mathrm{~g}$ poured into a reaction flask of the $50 \mathrm{ml}$ capacity, equipped with a reflux condenser, bubbler to bring chlorine in (glass tube), magnetic stirrer and thermometer. The flask was placed in thermostat oil bath of the $500 \mathrm{ml}$ capacity. The temperature of about $50^{\circ} \mathrm{C}$ was kept inside the reactor. Gaseous chlorine was brought in

from a pressure cylinder (by means of the glass tube), the flow was controlled with a flowmeter. The reaction was performed for 8 hours, the speed of chlorine adding amounted to about $5 \mathrm{~g} /$ hour. The analytical samples of about $0,2 \mathrm{~g}$ weight, were taken after introducing 1 equivalent of chlorine and then a few times during the introduction of the second equivalent. The samples were analyzed using the GC method: gas chromatograph with the FID detector, carrier gas - argon, the chromatography column - Megabor DB-1, 30 meters long, ID 0,53 mm, 1,5 $\mu \mathrm{m}$, produced by J\&Scientific. The temperature of the column:

$1^{\circ} 100^{\circ} \mathrm{C}$ for 5 minutes, $\Delta \mathrm{t} 6^{\circ} \mathrm{C} / \mathrm{min}$ from 100 to $160^{\circ} \mathrm{C}$, $2^{\circ} \Delta \mathrm{t} 15^{\circ} \mathrm{C} / \mathrm{min}$ from 160 to $230^{\circ} \mathrm{C} 230^{\circ} \mathrm{C}$ for 5 minutes, The temperature of the injector: $250^{\circ} \mathrm{C}$, the temperature of the detector: $260^{\circ} \mathrm{C}$.

The chlorophenol sample in the amount of $0,16 \mathrm{~g}-$ $0,19 \mathrm{~g}$ was dissolved in $10 \mathrm{ml}$ of methanol, $0.1 \mu \mathrm{l}$ of the prepared solution was injected into the column, retention times in the conditions of chromatography are as follows: phenol $~ 3.9$ min., 2-chlorophenol $\sim 4.4$ min., 2,4dichlorophenol $\sim 8.9$ min., 4-chlorophenol $\sim 9.5 \mathrm{~min}$., 2,6-dichlorophenol $\sim 9.8$ min., 2,4,6-trichlorophenol $13.4 \mathrm{~min}$. The content was calculated by peak area normalisation. The results of the experiment are presented in Table 2. 
Table 2. The course of phenol chlorination with chlorine

\begin{tabular}{|c|c|c|c|c|c|c|c|}
\hline \multirow{2}{*}{ Sample } & \multicolumn{6}{|c|}{ Composition of chlorophenols [\% GC] } & \multirow{2}{*}{$p-/ o-$} \\
\hline & phenol & $0-$ & $2,4-$ & $p-$ & $2,6-$ & $2,4,6-$ & \\
\hline 1 & 10.3 & 32.3 & 6.4 & 50.8 & 0.2 & 0.0 & 1.6 \\
\hline 2 & 0.0 & 20.7 & 47.4 & 27.8 & 3.9 & 0.3 & - \\
\hline 3 & 0.0 & 14.7 & 62.3 & 16.7 & 5.4 & 0.7 & - \\
\hline 4 & 0.0 & 12.1 & 68.9 & 11.6 & 6.7 & 0.8 & - \\
\hline 5 & 0.0 & 9.4 & 76.50 & 7.1 & 6.0 & 1.1 & - \\
\hline 6 & 0.0 & 5.0 & 85.4 & 1.3 & 7.0 & 1.4 & - \\
\hline 7 & 0.0 & 0.5 & 88.9 & 0.0 & 7.4 & 2.8 & - \\
\hline
\end{tabular}

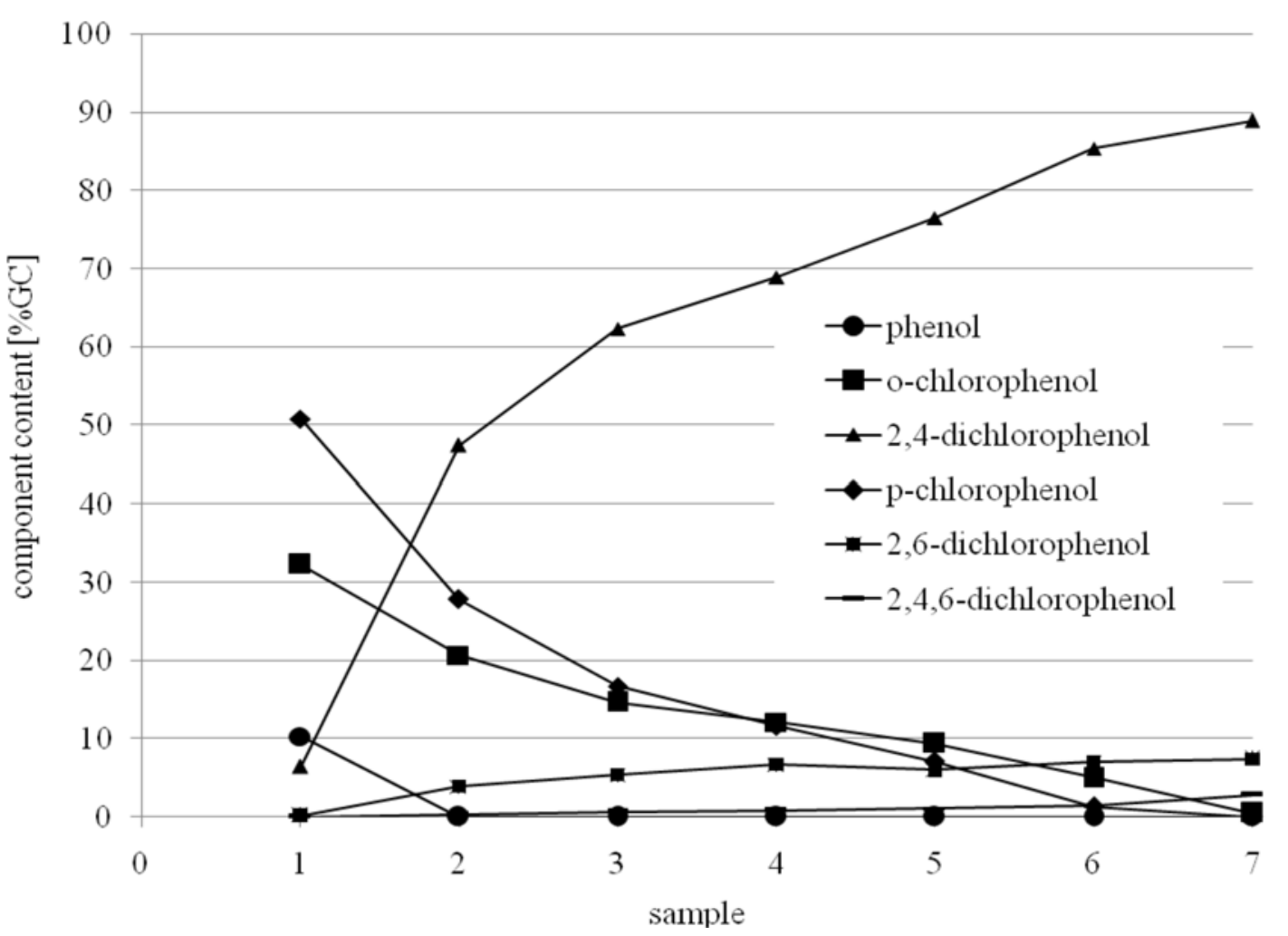

Figure 1. The composition of reaction mixture changes during phenol chlorination with chlorine

\section{Results}

Chlorination of phenol in the para- position at the monochlorination stage is much faster than in the ortoone. Substitution of the second chlorine atom occurs easier in the $p$-chlorophenol molecule than in $o$-chlorophenol one. The formation the 2,6-dichloro isomer proceeds at the same rate, proportional to that of chlorine brought in, but is much slower than that for the 2,4- isomer. The maximal content of 2,4-dichlorophenol in the post-chlorination mass is about $89 \%$. Chlorination of o-chloroph- enol to the end gives larger amount of trichlorophenol (overchlorination).

Contaminants of 2,4-D obtained from technical 2,4dichlorophenol, production wastes

2,4-dichlorophenol is mainly used for the production of 2,4-D. The by-products, formed during the unselective chlorination influence the amount of wastes in the production of 2,4-D production, which is presented below.

Technical 2,4-dichlorophenol containing $89 \%$ of the main component was treated with soda lye of the $50 \%$

Table 3. Mass after the condensation

\begin{tabular}{|c|c|c|c|}
\hline $\begin{array}{l}\text { Composition of mass after reaction } \\
\text { [\%] }\end{array}$ & & $\begin{array}{l}\text { Composition of phenol derivatives } \\
{[\% \text { GC] }}\end{array}$ & \\
\hline $\begin{array}{l}\text { chlorophenoxyacetic acids } \\
\text { chlorophenols }\end{array}$ & 31.5 & $\begin{array}{l}\text { o-chlorophenoxyacetic acid } \\
p \text {-chlorophenoxyacetic acid } \\
\text { 2,6-dichlorophenoxyacetic acid } \\
\text { 2,4- dichlorophenoxyacetic acid } \\
\text { 2,4,6-trichlorophenoxyacetic acid } \\
\text { o-chlorophenol } \\
\text { 2,4-dichlorophenol } \\
p \text {-chlorophenol } \\
\text { 2,6-dichlorophenol } \\
\text { 2,4,6-trichlorophenol }\end{array}$ & $\begin{array}{r}2.5 \\
0.5 \\
7.4 \\
84.6 \\
1.2 \\
0.0 \\
2.2 \\
0.0 \\
1.1 \\
0.4\end{array}$ \\
\hline
\end{tabular}


Table 4. The product and the wastes after crystallization

\begin{tabular}{|l|c|l|l|}
\hline Composition of 2,4-DNa paste & \multicolumn{2}{l|}{ Derivatives of phenol in wastes from crystallization 2,4-D } \\
[\% GC] & 0.28 & & \\
\hline chlorophenols & 1.99 & & $2.5 \%$ \\
o-chlorophenoxyacetic acid & 0.41 & chlorophenoxyacetic acids & $0.5 \%$ \\
p-chlorophenoxyacetic acid & 0.90 & chlorophenols & \\
2,6-dichlorophenoxyacetic acid & 95.6 & & \\
2,4- dichlorophenoxyacetic acid & 0.34 & & \\
2,4,6-trichlorophenoxyacetic acid & & & \\
\hline
\end{tabular}

Table 5. The contents of PCDD and PCDF congeners in the after-run in the distillation of 2,4-dichlorophenol x)

\begin{tabular}{|c|c|c|c|}
\hline \multirow{2}{*}{$\begin{array}{l}\text { Congener } \\
\text { PCDDs/PCDFs }\end{array}$} & \multirow{2}{*}{$\begin{array}{l}\text { WHO } \\
\text { TEF }\end{array}$} & Congener mass (mi) & Partial TEQ (mi TEF) \\
\hline & & $\mathrm{ng} / \mathrm{g}$ & $\mathrm{ng}-\mathrm{TEQ} / \mathrm{g}$ \\
\hline $2,3,7,8-\mathrm{TeCDD}$ & 1 & 2.32 & 2.3200 \\
\hline $1,2,3,7,8-\mathrm{PeCDD}$ & 1 & 51.71 & 51.7100 \\
\hline $1,2,3,4,7,8-\mathrm{HxCDD}$ & 0.1 & 0.28 & 0.0280 \\
\hline 1,2,3,6,7,8-HxCDD & 0.1 & 16.22 & 1.6220 \\
\hline $1,2,3,7,8,9-\mathrm{HxCDD}$ & 0.1 & 6.63 & 0.6630 \\
\hline 1,2,3,4,6,7,8-HpCDD & 0.01 & 0.76 & 0.0076 \\
\hline OCDD & 0.0001 & 3.11 & 0,0003 \\
\hline $2,3,7,8-\mathrm{TeCDF}$ & 0.1 & 10.69 & 1.0690 \\
\hline $1,2,3,7,8-\mathrm{PeCDF}$ & 0.05 & 1.45 & 0.0725 \\
\hline $2,3,4,7,8-\mathrm{PeCDF}$ & 0.5 & 1.50 & 0.7500 \\
\hline $1,2,3,4,7,8-\mathrm{HxCDF}$ & 0.1 & 0.55 & 0.0550 \\
\hline $1,2,3,6,7,8-\mathrm{HxCDF}$ & 0.1 & 4.58 & 0.4580 \\
\hline $1,2,3,7,8,9-\mathrm{H} \times \mathrm{CDF}$ & 0.1 & 3.16 & 0.3160 \\
\hline $2,3,4,6,7,8-\mathrm{HxCDF}$ & 0.1 & 0.17 & 0.0170 \\
\hline $1,2,3,4,6,7,8-\mathrm{HpCDF}$ & 0.01 & 5.90 & 0.0590 \\
\hline $1,2,3,4,7,8,9-\mathrm{HpCDF}$ & 0.01 & 0.00 & 0.0000 \\
\hline OCDF & 0.0001 & 67.75 & 0.0068 \\
\hline Summarised results in & $Q / g^{x)}$ & & $59.15 \pm 0.05$ \\
\hline
\end{tabular}

${ }^{x)}$ Assay of PCDD and PCDF was done by A. Grochowalski in the Laboratory For Trace Organic Analysis of Cracow University of Technology. Value of TEQ corresponds to the mass of the congener in the sample (mi) and TEF (the relative toxicity of a specific congener related to $2,3,7,8-\mathrm{TCDD}$ toxicity which is 1 ).

Table 6. The chlorination of phenol with the use of Lewis acid catalysts

\begin{tabular}{|c|c|c|c|c|c|c|c|c|c|}
\hline \multirow{2}{*}{ Attempt } & \multirow{2}{*}{ Catalyst } & \multirow{2}{*}{$\begin{array}{c}\text { Amount } \\
{[\%]}\end{array}$} & \multicolumn{6}{|c|}{ Composition of chlorophenols [\%GC] } & \multirow{2}{*}{$p-/ 0-$} \\
\hline & & & phenol & $0-$ & $2,4-$ & $p-$ & 2,6 & $2,4,6-$ & \\
\hline \multirow{3}{*}{1} & \multirow{3}{*}{$\mathrm{FeCl}_{3}$} & \multirow{3}{*}{0.3} & 8.9 & 34.6 & 14.1 & 42.2 & 0.2 & 0.0 & 1.2 \\
\hline & & & 0.0 & 5.4 & 88.3 & 0.4 & 4.7 & 1.2 & - \\
\hline & & & 0.0 & 2.0 & 90.3 & 0.0 & 5.2 & 1.6 & - \\
\hline \multirow{3}{*}{2} & \multirow{3}{*}{$\mathrm{ZnCl}_{2}$} & \multirow{3}{*}{0.3} & 32.9 & 27.6 & 4.4 & 35.0 & 0.0 & 0.0 & 1.3 \\
\hline & & & 0.0 & 5.5 & 85.4 & 1.9 & 6.0 & 1.2 & - \\
\hline & & & 0.0 & 0.6 & 87.7 & 0.0 & 8.5 & 3.2 & - \\
\hline \multirow{3}{*}{3} & \multirow{3}{*}{$\mathrm{AlCl}_{3}$} & \multirow{3}{*}{0.3} & 15.4 & 29.5 & 6.7 & 48.2 & 0.2 & 0.0 & 1.6 \\
\hline & & & 0.0 & 3.9 & 86.86 & 1.2 & 7.2 & 1.0 & - \\
\hline & & & 0.0 & 1.4 & 89.6 & 0.0 & 8.3 & 1.6 & - \\
\hline
\end{tabular}

concentration, increasing $\mathrm{pH}$ up to 9 . An aqueous $70 \%$ solution of chloroacetic acid (MCA) was added dropwise (1,1 equivalent). The temperature of $105^{\circ} \mathrm{C}$ was maintained. During soda lye addition, $\mathrm{pH}$ about 9,0 was kept. When the reaction was over the analysis of the post-condensation mass composition was done, revealing the yield of the reaction as $96.3 \%$.

\section{Results}

In the mixture of chlorophenols that did not react, isomers 2,6-DCP and 2,4,6-trichlorophenol were enriched in comparison to technical 2,4-D. It proves that they are less active, which is probably caused by steric reasons (chlorine atoms in the 2,6- position make access to the hydroxyl group difficult).
The crystallization of 2,4-D from alkaline mass after the reaction

Hot condensation mass was diluted with water to $20 \%$ concentration of chlorophenoxyacetic acids; after cooling it was filtered off with the use of vacuum filter, the sediment was washed on the filter with $50 \mathrm{~g}$ of water. The wet, monohydrate paste of 2,4-D sodium salt whose composition, according to GC was presented in table 4, wastes containing $2,5 \%$ of phenoxyacetic acids and $0,5 \%$ of chlorophenols mixture were obtained.

\section{Results}

The content of the 2-chlorophenoxyacetic acid, whose salt is difficult to dissolve in water is limited by the quality standard of 2,4-D. Its content in the product is about $2 \%$. The purity of 2,4-D acid after crystallization of so- 
Table 7. Phenol chlorination in the presence of tertiary amines

\begin{tabular}{|c|c|c|c|c|c|c|c|c|}
\hline \multirow{2}{*}{ Attempt } & \multirow{2}{*}{$\begin{array}{l}\text { Catalyst } \\
\text { amount [g] }\end{array}$} & \multicolumn{6}{|c|}{ composition of chlorophenols [\%GC] } & \multirow{2}{*}{$p-/ 0-$} \\
\hline & & phenol & $0-$ & $2,4-$ & $p-$ & $2,6-$ & $2,4,6-$ & \\
\hline \multirow{2}{*}{1} & \multirow{2}{*}{$\begin{array}{l}\text { pyridine } \\
0,08\end{array}$} & 5.0 & 32.1 & 10.5 & 52.1 & 0.4 & 0.0 & 1.5 \\
\hline & & 0.0 & 1.6 & 86.9 & 0.0 & 8.6 & 2.6 & - \\
\hline \multirow{2}{*}{2} & \multirow{2}{*}{$\begin{array}{l}\text { triethylamine } \\
0,1\end{array}$} & 1.3 & 31.2 & 15.6 & 51.3 & 0.6 & 0.0 & 1.6 \\
\hline & & 0.0 & 0.2 & 84.8 & 0.0 & 8.5 & 6.4 & - \\
\hline \multirow{2}{*}{3} & \multirow{2}{*}{$\begin{array}{l}\mathrm{AAA}^{\mathrm{xx})} \\
0,14\end{array}$} & 8.7 & 31.3 & 9.3 & 50.4 & 0.3 & 0.0 & 1.6 \\
\hline & & 0.0 & 3.6 & 85.5 & 0.0 & 8.5 & 2.4 & - \\
\hline \multirow{2}{*}{4} & \multirow{2}{*}{$\begin{array}{l}\text { DMF } \\
0,07\end{array}$} & 8.7 & 31.3 & 9.3 & 50.4 & 0.3 & 0.0 & 1.6 \\
\hline & & 0.0 & 3.6 & 85.5 & 0.00 & 8.5 & 2.4 & - \\
\hline \multirow{2}{*}{5} & \multirow{2}{*}{$\begin{array}{l}\text { 4-picoline } \\
0,09\end{array}$} & 8.5 & 31.3 & 8.7 & 51.2 & 0.3 & 0.0 & 1.6 \\
\hline & & 0.0 & 4.0 & 86.2 & 0.2 & 7.9 & 1.7 & - \\
\hline
\end{tabular}

${ }^{\mathrm{x})} \mathrm{AAA}$ - dimethylaminoacetic acid dimethylamide

Table 8. Phenol chlorination with chlorine in the presence of Lewis bases - aromatic and aliphatic sulfides

\begin{tabular}{|c|c|c|c|c|c|c|c|c|}
\hline \multirow{2}{*}{ Attempt } & \multirow{2}{*}{ Catalyst } & \multicolumn{6}{|c|}{ Composition of chlorophenols [\%GC] } & \multirow{2}{*}{$p-\%-$} \\
\hline & & phenol & $0-$ & $2,4-$ & $p-$ & $2,6-$ & $2,4,6-$ & \\
\hline \multirow{2}{*}{1} & \multirow{2}{*}{ DPS (diphenylsulfide) } & 21.9 & 27.9 & 7.4 & 42.8 & 0.0 & 0.0 & 1.5 \\
\hline & & 0.0 & 0.8 & 91.2 & 0.0 & 5.3 & 2.6 & - \\
\hline \multirow{2}{*}{2} & \multirow{2}{*}{ DBS (dibenzylsulfide) } & 26.6 & 22.5 & 3.3 & 44.1 & 0.0 & 0.0 & 2.0 \\
\hline & & 0.0 & 0.41 & 88.6 & 0.0 & 5.3 & 4.9 & - \\
\hline \multirow{2}{*}{3} & \multirow{2}{*}{ 1,3-dithiolan } & 30.1 & 22.3 & 3.8 & 42.9 & 0.0 & 0.0 & 1.9 \\
\hline & & 0.0 & 1.6 & 86.8 & 0.0 & 4.9 & 3.2 & - \\
\hline \multirow{2}{*}{4} & \multirow{2}{*}{ 1,4-dithiane } & 26.4 & 25.7 & 2.6 & 40.6 & 0.0 & 0.0 & 1.6 \\
\hline & & 0.0 & 1.6 & 89.7 & 0.0 & 6.4 & 2.3 & - \\
\hline \multirow{2}{*}{5} & \multirow{2}{*}{ dioctyl sulfide } & $32 ., 5$ & 22.6 & 2.3 & 42.0 & 0.0 & 0.0 & 1.9 \\
\hline & & 0.0 & 1.7 & 88.4 & 0.0 & 5.7 & 1.8 & - \\
\hline \multirow{2}{*}{6} & \multirow{2}{*}{ thiophene } & 30 & 24,8 & 7,8 & 35,5 & 0,4 & 0,0 & 1.4 \\
\hline & & 0.0 & 0.2 & 84.7 & 0.2 & 8.1 & 6.2 & - \\
\hline \multirow{2}{*}{7} & \multirow{2}{*}{ 5,14-dithiooctadecan } & 29.5 & 24.5 & 6.6 & 38.5 & 0.2 & 0.0 & 1.6 \\
\hline & & 0.0 & 2.7 & 86.1 & 0.4 & 6.1 & 3.7 & - \\
\hline
\end{tabular}

dium salt is maximally $95-96 \%$ of 2,4- isomer. During the crystallization chloroorganic wastes are separated chlorophenoxyacetic acids and chlorophenols in the amount of about $9.5 \%$ referred to the final product, the main component is the easily soluble $2,6-\mathrm{D}$ isomer.

\section{The Distillation of 2-chlorophenol from technical $89 \%$ 2,4-DCP}

Technical 2,4-dichlorophenol was placed in a distillation flask with a thermometer equipped with a Vigreux column and distillation adapter with Liebig's condenser. The whole set was connected to the vacuum line which contains the water pump and the manometer. The flask was heated on an oil bath. The distillation was carried out at $50 \mathrm{mmHg}$. The fraction of $o$-chlorophenol boiling at the temperature of $90^{\circ} \mathrm{C}$ was taken. The after-run was analyzed to check the dioxins and dibenzofurans (PCDD/ F) contents. The results are presented in table 5 .

\section{Results}

Separation of $o$-chlorophenol from raw 2,4dichlorophenol with the aid of vacuum distillation in order to increase the 2,4-D standard creates too large amounts of polichlorodibenzodioxins and polichlorodibenzofurans. In the after-run the most toxic 2,3,7,8-TCDD and TCDF are also present.

The chlorination of melted phenol with chlorine in the presence of Lewis acids

Lewis acids belong to the most popular catalysts used in the electrophylic substitution. Their influence on the regioselectivity of chlorine substitution process in the 2,4dichlorophenol synthesis was examined.

\section{Results}

No crucial improvement of reaction selectivity was noticed. In the samples containing iron chloride and zinc chloride the decrease of $p$ - $/ o$-ratio in monochlorination step was noticed.

It can be clearly seen that there is a tendency of 2,6isomer to decrease and 2,4-isomer to increase in the reaction in the presence of iron chloride.

The chlorination of phenol with chlorine in the presence of Lewis acids and combined catalysts

The influence of the addition of some amines, amides, aromatic and aliphatic sulfides and organic sulfide - Lewis acid combined as catalysts on chlorination selectivity in the melted state was checked. The reaction was carried out according to the procedure of phenol chlorination without using the catalysts presented above. The results are collected in Table 7, 8 and 9.

\section{Results}

The results are comparable to the attempts of pure phenol chlorination without using catalysts. The tendency of $o$-chlorophenol and 2,6-dichlorophenol increasing amounts is noticed.

\section{Results}

The catalysts investigated with the exception of DPS do not considerably influence the selectivity of chlorination. 
Table 9. Phenol chlorination with chlorine using catalysts - Lewis acid and Lewis base combined

\begin{tabular}{|c|c|c|c|c|c|c|c|c|}
\hline \multirow{2}{*}{ Attempt } & \multirow{2}{*}{$\begin{array}{l}\text { Catalyst } \\
\text { amount [\%] }\end{array}$} & \multicolumn{6}{|c|}{ Composition of chlorophenols } & \multirow{2}{*}{$p$-/o- } \\
\hline & & phenol & $0-$ & $2,4-$ & $p-$ & $2,6-$ & $2,4,6-$ & \\
\hline \multirow{2}{*}{1} & \multirow{2}{*}{$\begin{array}{l}\text { DPS, } \mathrm{AlCl}_{3}, \\
0,2 / 0,3\end{array}$} & 30.7 & 20.8 & 5.3 & 43.1 & 0.1 & 0.0 & 2.1 \\
\hline & & 0.0 & 1.4 & 89.5 & 0.0 & 5.4 & 3.1 & - \\
\hline \multirow{2}{*}{2} & \multirow{2}{*}{$\begin{array}{l}\text { DPS, } \mathrm{FeCl}_{3}, \\
0,2 / 0,3\end{array}$} & 1.4 & 27.7 & 15.2 & 54.9 & 0.6 & 0.3 & 2.0 \\
\hline & & 0.0 & 0.0 & 94.7 & 0.0 & 3.8 & 1.5 & - \\
\hline \multirow{2}{*}{3} & \multirow{2}{*}{$\begin{array}{l}\text { DPS, } \mathrm{ZnCl}_{2} \\
0,2 / 0,3\end{array}$} & 16.1 & 26.3 & 2.9 & 52.9 & 0.3 & 0.0 & 2.0 \\
\hline & & 0.0 & 3.2 & 90.8 & 0.5 & 4.4 & 1.0 & - \\
\hline
\end{tabular}

Table 10. The GC analysis of the after-chlorination mixture

\begin{tabular}{|c|c|c|c|c|c|c|c|c|c|c|c|}
\hline \multirow{2}{*}{ Catalyst } & \multicolumn{11}{|c|}{ Composition of mixture after chlorination [\%GC] } \\
\hline & phenol & $0-$ & $2,4-$ & $p-$ & $2,6-$ & $2,4,6-$ & chlorophenols [\% GC] & $\mathrm{X} 1$ & $\times 2$ & $\times 3$ & $\Sigma X$ \\
\hline \multirow{4}{*}{$\begin{array}{l}\text { DPS } \\
2 \% \\
\mathrm{FeCl}_{3} \\
0.7 \%\end{array}$} & 25.6 & 15.0 & 6.4 & 50.0 & 0,2 & 0,8 & 98.0 & 2.0 & 0.0 & 0.0 & 2.0 \\
\hline & & 14.5 & 37.1 & 44.3 & 1 & 1,4 & 98.3 & 0.0 & 0.9 & 0.0 & 1.8 \\
\hline & & 8.8 & 64.6 & 21.2 & 1,8 & 2.0 & 98.4 & 0.3 & 1.1 & 0.3 & 1.7 \\
\hline & & 1.4 & 90.2 & 0.8 & 2,8 & 3,5 & 98.7 & 0.0 & 0.4 & 0.9 & 1.3 \\
\hline \multirow{4}{*}{$\begin{array}{l}\text { DPS } \\
2 \%\end{array}$} & 4.2 & 22.1 & 8.2 & 62.8 & 0.2 & 0.4 & 97.9 & 2 & 0.1 & 0.0 & 2.1 \\
\hline & & 14.0 & 49.9 & 32.1 & 1.3 & 0.8 & 98.1 & 1.3 & 0.7 & 0.0 & 2.0 \\
\hline & & 3.5 & 88.3 & 1.1 & 3.0 & 2.3 & 98.2 & 0.7 & 1.0 & 0.2 & 1.9 \\
\hline & & 0.5 & 89.7 & 0.0 & 3.6 & 4.7 & 98.5 & 0.2 & 0.9 & 0.4 & 1.5 \\
\hline
\end{tabular}

The tendency of 2,6-DCP isomer decreasing amount is observed.

\section{Results}

Using Lewis acid, especially $\mathrm{FeCl}_{3}$ combined with diphenyl sulfide, unexpectedly enables the selective chlorination of monochlorophenols to $2,4-\mathrm{DCP}$ without an undesirable increase of 2,6-DCP and 2,4,6-TCP contents. A considerable improvement of chlorination selectivity is noticed.

The transformations of DPS under the conditions of 2,4DCP synthesis $^{34}$

Diphenyl sulfide (DPS) is liquid (oil), the colourless substance with a characteristic, strong smell, the boiling point at $295^{\circ} \mathrm{C}$ and the melting point at $-40^{\circ} \mathrm{C}$. Practically insoluble in water, it is miscible with benzene, diethyl ether, carbon disulfide and acetone.<smiles>c1ccc(Sc2ccccc2)cc1</smiles>

During the GC analysis of 2,4-dichlorophenol obtained by phenol chlorination with the addition of DPS, it can be observed that some signals of a few substances having retention time longer than chlorophenols appear. Those signals are not noticed during phenol chlorination without the addition of DPS. It is probable that they are products of DPS transformations during phenol chlorination.

In the table below the changes of „strange” peaks composition during phenol chlorination with the addition of DPS and DPS with iron chloride are presented.

Considering the DPS structure, some assumptions can be made: electrophylic substitution proceeds easily and under the conditions of 2,4-dichlorophenol synthesis DPS is chlorinated, which leads to obtaining the mixture of DPS chloroderivatives:

-2-chlorodiphenylsulfide and 4-chlorodiphenylsulfide; $\mathrm{FW}=220$,
- 2,2'-dichlorodiphenylsulfide; 2,4'-dichlorodichlorodiphenylsulfide and 4,4'-dichlorodiphenylsulfide; $\mathrm{FW}=254$,

- 2,4,4'-trichlorodiphenylsulfide; 2,2,4'-trichlorodiphenylsulfide; 2,4,2'-trichlorodiphenylsulfide; 2,2,2'trichlorodiphenylsulfide; $\mathrm{FW}=288$.

The remains of DPS and the more chlorinated derivatives probably also occur. Substances X1, X2, X3 are found in 2,4-DCP in the amounts of decimals of percentage. In order to analyze their structure indirect methods were used which were based on their separation from 2,4dichlorophenol with the aid of preparative chromatography and then the GC/MS analysis and ${ }^{1} \mathrm{H}$ NMR.

Sample (1) containing $9 \mathrm{~g}$ of chlorophenol with the remains of DPS derivatives was treated with aqueous $\mathrm{NaOH}$ solution up to $\mathrm{pH} 10$. The mixture was extracted with hexane. The layer of hexane was isolated, dried over $\mathrm{MgSO}_{4}$, filtered and removed by means of a vacuum evaporator. About $100 \mathrm{mg}$ of substance was obtained, which was investigated by the preparative TLC method (eluent -heptan). Two fractions were found:

- top fraction (2): the main component ( GC 21.5 $\min$.),

- bottom fraction (3): a mixture of two components.

After the analysis of the top fraction (2) with the aid of GC/MS and ${ }^{1} \mathrm{H}$ NMR it was established that it is a mixture of two DPS chlorodervatives whose molecular mass is 254 - there are probably:

- about $60 \%$ of 4,4'-dichlorodiphenylsulfide

Table 11. The GC analysis after DPS chlorination

\begin{tabular}{|c|c|c|c|c|}
\hline \multirow{3}{*}{ Attempt } & \multicolumn{4}{|c|}{$\mathrm{GC}$ in conditions of 2,4-DF analyze [\%GC] } \\
\cline { 2 - 5 } & $\mathrm{DPS}$ & $\mathrm{X} 1$ & $\mathrm{X} 2$ & $\mathrm{X} 3$ \\
& $\begin{array}{c}\mathrm{Rt} 17.9 \\
\text { min. }\end{array}$ & $\begin{array}{c}\mathrm{Rt} 19.8 \\
\text { min. }\end{array}$ & $\begin{array}{c}\text { Rt 21.9 } \\
\text { min. }\end{array}$ & $\begin{array}{c}\text { Rt 24.2 } \\
\text { min. }\end{array}$ \\
\hline 4 & 5.3 & 65.5 & 23.9 & - \\
\hline 5 & 0.5 & 8.6 & 81.3 & 2.6 \\
\hline
\end{tabular}<smiles>Clc1ccc(Sc2ccc(Cl)cc2)cc1</smiles> 
- about $40 \%$ of other dichlorosubstituted derivative of DPS 50g of DPS was chlorinated with gaseous chlorine at the temperature $50-80^{\circ} \mathrm{C}$ for about 5 hours. During the chlorination the GC analyses were taken. The results of the analyses are presented in Table 11.

GC/MS analysis was performed for chloroderivatives DPS (5) mixture. It was identified as follows:

- traces of DPS $\mathrm{M}^{+\cdot} \cdot \mathrm{m} / \mathrm{z}$ 186, Rt 17,9 min.

- two isomers of monochlorodiphenylsulfide $\mathrm{M}^{+\cdot} \mathrm{m} / \mathrm{z}$ 220, no separation GC, Rt 19,8 min.<smiles>Clc1ccc(Sc2ccccc2)cc1</smiles>

- three isomers of dichlorodiphenylsulfide $\mathrm{M}^{+\cdot} \cdot \mathrm{m} / \mathrm{z}$ 254, no separation GC, Rt 21.9 min.<smiles>Clc1ccc(Sc2ccccc2)cc1</smiles>

- trichlorodiphenylsulfide $\mathrm{M}^{+\cdot} \cdot \mathrm{m} / \mathrm{z} 288$, Rt $24.2 \mathrm{~min}$.<smiles>Clc1ccc(Sc2ccc(Cl)c(Cl)c2)cc1</smiles>

Raw substance (5) contains about $80 \%$ of the main component, according to the GC analysis. According to the TLC analysis, sample (5) contains the main substance of the highest Rf, (eluent: heptane, two times developed TLC), a large amount of another component, whose Rt is lower and some amount of other substances.

Substance (5) was separated into contents.

The main fraction was isolated by the contaminants having been washed off with heptane.

The main substance is the crystal white solid. It was marked as (5a).

After recrystallization from heptane the melting point was $94-95^{\circ} \mathrm{C}$.

Another component of the mixture was separated from the main substance and others with the aid of column chromatography on silica gel. To separate it the remains of the main purifying substance was used with the aid of the method mentioned above. After two times of chromatograpic purifying about $1,5 \mathrm{~g}$ of substance was obtained in the form of colourless oil. The sample was marked as (5b).

GC performed under the conditions suitable for 2,4DCP proved that the main substance (5a) and the other component of the separated mixture marked $(5 b)$ have the same retention time (21,5 min.) and they are not possible to separate under the analysis condition, although the TLC analysis shows that these two substances are probably position isomers of the chlorinated DPS. Similar conclusions can be generalized from the GC/MS analysis and 1H NMR analysis.

The TLC comparison was performed, the following samples were put on the silica gel plate: (5b), (2) and the mixture of these substances. The plate was developed 2 times, eluent-heptane. The conclusion after the separation is that these are the same substances.

The comparison of retention times of separated DPS chloroderivatives (5) and substances X1, X2, X3 from test
(1) with the aid of TLC and GC proved that the compounds are the same.

During the chlorination of DPS with gaseous chlorine under the conditions of 2,4-DCP synthesis the formation of different compounds from DPS with aromatic hydrogens, substituted by two chlorine atoms is not observed in a sufficient amount.

The main derivatives of DPS occurring in 2,4dichlorophenol are dichlorosubstituted DPS isomers and small amounts of trichlorosubstituted DPS and monochloro DPS.

\section{The removing of catalysts from dichlorophenol}

2,4-dichlorophenol obtained in phenol chlorination in the presence of catalysts was washed out with hydrochloric acid. It was neutralized to $\mathrm{pH}>10.5$ and diluted with water to obtain the $50 \%$ solution. Suspension of active carbon and silicon sorbent was added to such sodium chlorophenolate in the way to make the ratio of 2,4dichlorophenol to active carbon equal 0,008 by weight. The chlorophenolate with sorbents were stirred for 30 minutes. Carbon,

Table 12. The purification of dichlorophenol on the sorbents

\begin{tabular}{|l|c|c|}
\hline $\begin{array}{l}\text { content of iron } \\
{[\mathrm{ppm}]}\end{array}$ & $\begin{array}{c}\text { derivatives of DPS } \\
{[\%]}\end{array}$ & $\begin{array}{c}\text { PCDD/F } \\
{[\mathrm{TEQ} \mathrm{ng} / \mathrm{g}]}\end{array}$ \\
\hline$<5$ & $<0.001$ & 0.027 \\
\hline
\end{tabular}

which was brought in was then filtered off with the sorbent. The content of iron and high-molecule chloroorganic compounds ( $\mathrm{PCDD} / \mathrm{F}$ and derivatives of DPS) in sodium chlorophenolate was investigated. The experiments shown above are desribed in patent application P-377671 35 . The results of the analyses are presented in Table 12.

\section{Results}

In the process of phenol chlorination to 2,4dichlorophenol in the presence of DPS and DPS with $\mathrm{FeCl}_{3}$, substitution at diphenyl sulfide with chlorine atoms occurs. Increasing the amount of chloro-DPS does not seem to influence the catalytic properties of sulfide. The organic and inorganic catalysts are successfully removed from technical 2,4-DCP with the aid of washing out with hydrochloric acid and the sorption on mineral sorbents. 2,4-DCP obtained by phenol chlorination contains trace amounts of PCDD/F contaminants allowed in the standards of technical products.

\section{CONCLUSION}

2,4-dichlorophenol is an itermediate in the synthesis of many active substances such as 2,4-dichlorophenoxyacetic acid (2,4-D), the herbicide of great importance in crops, rice and other cultivations. For the last three decades large interest in synthesis and technology of 2,4dichlorophenol (2,4-DCP), which is produced in the scale of tens thousands $\mathrm{Mg} / \mathrm{yr}$, has been observed.

The technology of 2,4-DCP is based on low regio- and chemoselective melted phenol chlorination with gaseous chlorine. The difficult to neutralize wastes and contaminants are the shortcomings of the technology. Interest in chlorophenols chemistry should be directly connected with 
the accident of dioxins contamination in Seveso in 1976, Directive 91/414/EEC about the reassessment and registration of pesticides and new law regulations regarding the matter of environment protection. Our research concentrated on the parameters of technology meaning such as the range of regioselective catalysts and their separation from the post-chlorination mass, danger of highly toxic dioxins, apperance and the limitation of wastes. In three groups of catalysts- Lewis acids, amines and bivalent sulfur compounds, no catalyst which influences para- and 2,4selectivity was found. Strongly para-regioselective amine catalysts used by Moszczyński in the synthesis of 4-chloro2-methylophenoxyacetic acid, which is an analog of 2,4$\mathrm{D}$, were found ineffective ${ }^{\mathbf{1 5}}$. The high activity of Lewis catalysts with bivalent sulfur co-catalysts known from Watson $^{7}$, Shelton ${ }^{19}$ and many other authors' publications was proved. Diphenyl sulfide (DPS), the most often used co-catalyst in this group, according to Watson ${ }^{17}$, was not converted in the chlorination and could be isolated and reused. Our research shows that it is converted during the chlorination into a few chloroderivatives, but it does not lead to the loss of catalytic activity. Many literature sources claim that during thermal or chemical decomposition of chlorophenols including 2,4-dichlorophenol, polichlorodibenzodioxins and polichlorodibenzofurans can be formed, but the presence of the most toxic congeners 2,3,7,8-TCDD and 2,3,7,8-TCDF has never been noticed. Dioxins formation is eliminated or limited by the presence of Lewis catalysts $1,2,26,27$. Our research proved that during the vacuum distillation of technical 2,4-DCP in spite of Lewis acids presence dioxins are formed, including the most toxic congeners 2,3,7,8-TCDD and 1,2,3,7,8PCDD (table 5). Considering many reports about obtaining trace amounts of phenoxyphenols, gemdichlorocyclohexenones, biphenyls and other similar compounds as contaminants during the synthesis, the method of organic and inorganic contaminants trace amounts, the elimination including the remains of catalysts removal with the aid of sorbents seems to be of great technical importance, which was published in Moszczyński, Białek and the others patent application ${ }^{35}$.

\section{LITERATURE CITED}

1. Mueller, F. \& Caillard, L. (1986). Ullmann's Encyclopedia of Industrial Chemistry (Vol A7). Chlorophenols. Verlag Chemie, Weinheim / Bergstr.

2. Desmurs, J.R. \& Ratton, S. (2000). Kirk-Othmer Encyklopedia of Chemical Technology. Chlorophenols. John Wiley \& Sons, Inc.

3. Moszczyński, W., Białek, A., Makieła, E. \& Rippel, B. (2008). Development of 2,4-D technology in Poland. Przem. Chem. 87(7), 757-759.

4. Cieślak, M., Koperska, M., Żołędziowska \& J., Kosińska K. (1969). Unpublished Report No. 7/19/21. IPO Library Warsaw.

5. Cattabeni, F., Cavallaro, A. \& Galli, G. (1978). Dioxyne, technological and chemical aspect. SP Medical and Scientific Books, New York, London.

6. Council Directive of 15 July 1991 Concerning the placing of plant protection products on the market (91/414/ EEC), OJ L 230,19.8.1991, p.1,

7. Watson, W.D. (1985). Regioselective Para Chlorination of Activated Aromatic Compounds. J. Org. Chem. 50, 2145-48.

8. Joester, M.D. \& Shaad, I.J. (1974). Hydrogen Bonding. Marcel Delker, New York.
9. Belany, L.J. (1958). The Infra-red Spectra of Complex Molecules $\left(2^{\text {nd }}\right.$ ed). Wiley, New York.

10. Caujolle, F., Fauran, F. \& Quan, D., Q., (1968) On the bond between bovine serum albumin and 6monoalkylated metacresols. C R Acad Sci Hebd Seances Acad Sci D. 267 (25):2213 - 2215.

11. Watson, W.D. (1974). Chlorination of Phenols with Chlorine and tert-Butyl Hypochlorite. A Comparison. J. Org. Chem., 39(8), 1160 - 1164.

12. Ogata, Y., Kimura, M., Kondo, Y., Katoh, H. \& Chen, F-C. (1984). J.Chem.Soc. P.T.II. 1984, 451 - 453.

13. Szekely, I. (1982). Ger. Pat. 3318791. (to CIBA-GEIGY).

14. Besson, B. \& Desmurs, J.R. (1989) U.S. Pat. 4855513. (to Rhône-Poulenc).

15. Moszczyński, W. (1998). The research for synthesis and production of 4-chloro-2-methylphenoxyacetic acid (MCPA). Prace Naukowe Instytutu Przemystu Organicznego "Organika".

16. Drahonowsky, J. \& Vacek, Z. (1971). Collect. Czech. Chem. Comm. 36, 3431 - 3440.

17. Watson, W.D. (1976). The regioselective para-chlorination ot 2-methylphenol. Tetrahedron Lett. 30, 2591 2594.

18. Ratton, S. (1987) Fr. Pat. 2584068, (to Rhone Poulenc Spec. Chim.).

19. Shelton, F.J., Wetzel, W.H., Wilkinson, J.L. \& Goodwin. R.J. (1977). U.S. Pat. 4160114 (to Reichhold Chemicals).

20. Tzimas, M. (1998). Eur. Pat. 0866048. (to UNIV. WALES SWANSEA).

21. Tzimas, M., Smith, D.E. and co-workers (1998). Eur. Pat. 0866049 (to UNIV. WALES SWANSEA).

22. Moszczyński, W., Białek, A., Makieła, E., Listopadzki, E. \& Rippel, B. (2007). Pl. Pat. 197863. (to IPO and RokitaAgro SA.)

23. Bukowska, B., Rychlik, B., Krokosz A. \& Michałowicz J. (2008). Phenoxyherbicides induce production of free radicals in human erythrocytes: Oxidation of dichlorodihydrofluorescin and dihydrodamine 123 by 2,4-DNa and MCPA-Na. Food Chem. Toxicol, 46, 1, 359 - 367. DOI: 10.1016/j.fct.2007.08.011

24. Abrahamsson, K. \& Xie, T., M. (1983). J. Chromatog. 279, $199-208$.

25. Kempf, H., Chamard, A., Desmurs, J. R., Dananche, J. \& Bauer, G. (1987). Poster Iieres Journées d'Electrochimie, Dijon, France.

26. Ratton, S. \& Desmurs, J.R. (1986). Fr. Pat. 2601001 (to Rhône-Poulenc Chimie).

27. Ratton, S. (1985). Brit. Pat. 2177396 (to RhônePoulenc Specialties Chimiques).

28. Besson, B., Desmurs, J.R. \& Jouve, I. (1987). Eur. pat. 283411. (to Rhône-Poulenc Chimie).

29. Desmurs, J.R. \& Ratton, S. (1989). U.S. Pat. 4853153 (to Rhone Poulenc Chimie).

30. Perwunina, R.L., Samsonow, D.P. \& Rakhmanowa, T.V. (1992). 2,3,7,8-Tetrachloro-p-dioksin in Russian Environmental Samples, Materials DIOX W92, 173 - 176.

31. Standarized Toolkit for Identification and Quantification of Dioxn and Furan Releases, 1-est edition, (2003), UN Environment Programm, UN EP Chemicals, Geneva.

32. Boddington, M.J., Gilman, A.P. \& Newhook R.C., (1990). Polichlorinated Dibenzodioxins and Dibenzofurans. Canadian Environmental Protection Act. List Assentment Report No.1.

33. Thompson, L.R. \& Kearney, J.K. (1981). U.S. Pat. 4272636 (to Dow Chemical Co.)

34. Moszczyński, W., Połeć, I., Białek, A., Makieła, E., Listopadzki, E. \& Rippel, B. (2003). Unpublished Report No 6T 090034 2002/C05821, Stage No 1B, IPO Library Warsaw.

35. Moszczyński, W., Białek, A. Makieła, E., Rippel, B., Okulewicz, Z., Dancewicz, G. (2006). Pl. Pat. Appl. P-377671. (to IPO and Rokita-Agro SA.) 